\title{
Evaluating the FRSC's "Don't Drink and Drive" Media Campaign in South-east, Nigeria: Effects on Motorists' Exposure and Compliance Levels
}

\author{
ANDREW HYACINTH NGENE ${ }^{a}$, LUKE IFEANYI ANORUE ${ }^{b}$ \\ a. Department of Mass Communication, Ibrahim Badamasi Babangida University, Lapai, 911101, Nigeria \\ b. Department of Mass Communication, University of Nigeria, Nsukka, 410001, Nigeria
}

KEYWORDS: Impaired Driving; Nigeria; Don't Drink and Drive; Compliance; Intervention Campaign

\begin{abstract}
:
\section{Background}

Several campaigns on road traffic accidents have been launched by the Federal Road Safety Corps (FRSC) of Nigeria in collaboration with the Beer Sectoral Group (BSG). One such campaign is the "Don't Drink and Drive" intervention launched in 2008. This intervention was initiated to discourage drunk-driving and to improve safety on Nigerian roads through awareness creation. While it is a fact that the the combined enforcement and public education roles of the stakeholders has enormous potentials to tackle drunk driving problems, indigenous empirical evaluation on drivers' exposure and compliance to such DDD messages is scanty. This paper therefore examined motorists' exposure to FRSC's "Don't Drink and Drive" media campaign in South-east, Nigeria and its effects on their compliance levels.
\end{abstract}

\section{Methods}

A descriptive survey was used to elicit information from 360 registered commercial and private drivers in three selected states (Anambra, Ebonyi and Enugu) in South-eastern region of Nigeria. A multistage sampling approach was adopted in the study. Specifically, a combination of simple random sampling techniques and a purposive sampling procedure was adopted to access respondents across the region under study. Participants volunteered to complete paper version of the questionnaire at their convenience. An independent-samples t-test, a one-way between-groups analysis of variance (ANOVA) and a chi-square test for odd ratio (OR) and relative risks (RR) were performed to test the variables of interests in the study.

\section{Results}

Among other findings, data revealed that in terms of the participants' level of exposure to the DDD campaign, significant differences were observed in age, education, income and number of years spent driving. We also found that drivers' agreement level of the contents of the DDD campaigns was appreciable. Results particularly suggest that the DDD campaigns had a significant impact on drivers' likelihood of avoiding alcohol when driving, reducing alcohol intake at other times and educating others on the danger of drunk driving.

\section{Conclusion}

We conclude that the DDD campaigns might be more effective when policy designers and interventionists concerned with road safety begin to focus on the differences in the demographic characteristics of the drivers. Nonetheless, we advised that the intervention should continue alongside the use of legal back-up (i.e., by imposing some sanctions on drunk drivers) for optimal performance, while campaign efforts should factor in the roles of multiple variables that have been raised in this study.

\section{INTRODUCTION}

Road traffic accidents all over the world are more than a safety problem. They comprise a general medical issue and need that requires prompt handling utilising general public health measures and approach. It is estimated, that 1.4 million people die on road traffic accidents, with about 20 to 50 million individuals debilitated yearly on a worldwide scale (WHO, 2020). Researchers are of the view that if unchecked, by the year 2020, road traffic accidents will rank third of all reasons for morbidity and mortality globally (Peden, 2005; Hazen $\&$ Ehiri, 2006; Mock et al., 2005; WHO, 2004). To this end, a number of anti-drunk driving initiatives were developed to nip the problem of drinking and driving in the bud. An example of such intervention is the Global Actions on Harmful Drinking which set out plans to build capacity, train and evaluate and share global best practices via a number of pilot programmes (International Alliance for Responsible Drinking [IARD], 2020). Between 2010 and 2017, the IARD in collaboration with indigenous trading companies, trade associations, government and non-governmental development partners operated pilot programmes in 11 countries (Cambodia, South Africa, China, Dominican Republic, Namibia, Mexico, Rus- sia, Thailand, Vietnam and Nigeria) (IARD, 2020). While this programme has continued to report appreciable progress, there have still been calls to further intensify efforts aimed at achieving a broader objective. In Africa (e.g., Burkina Faso, Cameroun, Gambia, Tanzania, etc), similar anti-drunk driving campaigns have been launched and implemented at several levels, however, the effectiveness of these intervention efforts have been affected by lack of capacity and resources (African Development bank Group, 2013).

In Nigeria where the present study is focused, Welcome and Pereverzev (2010) observe that approximately 50 per cent of road traffic accidents on Nigerian roads are linked with alcohol use. In Nigeria, it is common to see drivers consume alcohol at driver rest areas and towns where long distance trucks and buses stop, because these places are full of outlets selling licensed and locally made alcohol beverages (Ogazi \& Edison, 2012). Ogazi and Edison further argue that alcohol consumption is a common phenomenon among many commercial drivers driving long distances in Nigeria, especially in the Christian dominated southern and middle belt states. For this group of people, alcohol consumption is a central part of adult life and it performs a crucial role in the socio-cultural and economic activities (festival, fu- 
neral, wedding, night outings, etc) (Bennett et al. 1998). In a study conducted by CLEEN Foundation in 2013, it was reported that about 79 per cent of motorists reported that they "sometimes" or "always" take alcohol before driving (Ezemalu, 2013). The study also reported that 8 in 10 Nigerian drivers drive under the influence of alcohol. Because of this drink driving situation, drunk drivers are believed to be at a high risk of being involved in road traffic accidents. Although statistics about accidents caused by drunk driving are scanty, available data indicate that while most (60\%) of drink-related accidents involved drivers, a third and 8 per cent of others involved were pedestrians and cyclists respectively (Akintunde et al., 2019). Alcohol is also reported to be a major contributor to road accident throughout Nigeria (Ogazi \& Edison, 2012).

As a result, several campaigns on road traffic accidents (Elder et al., 2004; Asemah \& Omosotomhe, 2016) have been launched by the Federal Road Safety Corps (FRSC), an agency established by the Nigerian government in 1988 to oversee to issues on road safety. This agency in collaboration with some corporate organisations like Mobil Producing Nigeria (MPN), Guinness Nigeria Plc, Manufacturers Association of Nigeria (MAN) among others have in the past organised intervention campaigns on drunk-driving. One of such is the annual "Don't Drink and Drive" media campaign launched in 2008 by Nigeria Breweries Plc in partnership with the FRSC to discourage drunk-driving, and to improve safety on Nigerian roads through awareness creation. The campaign are often run towards the end of the year when there is perceived vehicular increase as a result of those who travel to celebrate the Christmas and New Year holidays. Radio and Television programmes, rallies, and other safety awareness campaigns are channels used to deliver these multiple messages aimed at preventing drunk driving. A more recent DDD campaigns were implemented for the year 2018, 2019 and 2020 editions. The Nigerian Breweries (the Beer Sectoral Group [BSG]) in association with the FRSC kicked off the campaigns aimed at creating safety awareness on Nigerian roads in order to reduce the dangers of drunk driving. The organisers of the campaigns employed the use of electronic, electronic media messages (e.g., DDD messages on social media links like https://fb.watch/3G1LzqnYqD/), fliers and free medical check-up exercise. Although the exercise has been conducted in several cities and towns across Nigeria, the expected decrease in drunk driving and its attending consequences has only been speculated. This is perhaps why Ogazi and Edison (2012) noted that the effectiveness of these campaigns is yet to be empirically evaluated. Nevertheless, the combined enforcement and public education roles played by the FRSC and her partners respectively always makes it a considerable potential for nipping the problem in the bud (Ogazi \& Edison, 2012).

In addition, despite the continuous emphasis placed on the dangers of alcohol-impaired driving by the (DDD) campaign messages, like "Stay alive don't drunk drive", "Life has no take two", "Only you can stop drunk-driving" among others, there seems to be a steady increase in the number of alcohol related traffic accidents on Nigerian roads (Casual observation). Public discussions with regards to the problem of drunk driving and its effects have therefore raised some objections as to the effectiveness of these campaign efforts. But indigenous empirical knowledge, which is peculiar to the Southern Nigerian context on exposure and compliance to such DDD messages are limited. This over the years has raised a fundamental question as to whether the intervention campaigns have some kind of impact on motorists. Consequently, this study attempts to provide answers to the following questions: (a) How exposed are motorists to this annual "Don't Drink and Drive" campaign? (b) To what extent do they agree with the messages contained in the "Don't Drink and Drive" campaign?, (c) What is the impact of "Don't Drink and Drive" campaigns on motorists' level of agreement with the content of the messages between those who were exposed to the messages and those who were not? and (d) What is the level of their self-reported compliance to "Don't Drink and Drive" campaign? By understanding respondents' pattern of exposure and perceived compliance to the messages, our study might inform a more effective future intervention programmes. As a result, the study examined motorists' exposure to FRSC's "Don't Drink and Drive" media campaign in South-east, Nigeria and its effects on compliance levels.

\section{LITERATURE REVIEW}

\subsection{Drinking and traffic injuries}

Drinking and driving has been identified as a problem which requires a multi-pronged, coordinated approach if it is to be effectively addressed. Assessing the prevailing knowledge, attitudes, and practices surrounding drink driving among 1187 road users in Cambodia, Bachani et al.(2016) reported that despite the belief that drinking and driving would increase the risk of an accident; a significant percentage of the respondents (37.1\%) have driven within 2 hours of drinking alcohol at least once in the 30 days preceding the survey. This proportion was particularly high among males aged 25 and 34 years at $49.2 \%$. Of those who reported drinking and driving, 76.5\% indicated they 'felt conscious enough' to drive at the time and $34.0 \%$ reported having 'no other available transportation options'. Similarly, Wang et al., (2018) found out that hour of the day, driver's age, driver's casualties and accident area have significant correlation with drunk driving. However, there was a slightly decrease by 0.995 per year with age and a slightly increase by 1.014 with time in the possibility of driving while intoxicated (DWI - which could mean that a driver has an alcohol content above the legal limit and she/ he is impaired while driving). Their study also revealed that DWI is more likely to cause death in traffic accidents $(\mathrm{OR}=$ 1.316) than driving under the influence of alcohol (DUI which could also suggest that a driver has a lower level of intoxication than DWI, but was still impaired). It was also found that drivers were more likely to die $(\mathrm{OR}=2.346)$ than be injured and live $(\mathrm{OR}=1.910)$ in DWI cases.

Therefore, to further establish the relative risk of death among road users, Damsere-Derry et al.(2017) revealed that accidents in Northern Ghana were extremely severe as 35\% of all injury related collisions were fatal. Males were six times more likely to die than females, while females were more likely to die as pedestrians (90\%) and males were more likely to die as riders/drivers (78\%). Pedestrians were three times more likely to die $(\mathrm{OR}=3.1 ; 95 \% \mathrm{CI}=2.4$ to 4.1$)$ compared with drivers/riders. Compared with casualties aged between 30 and 59 years, children under 10 years and the aged (60 years and above) were independently, two times more likely to die in traffic collisions. Consequently, the unanimous consensus among researchers (Bachani et al., 2016; Damsere-Derry et al., 2017 \& Wang et al., 2018) is on the need for social marketing, public education campaigns, enhanced enforcement, and programmes that either limit the number of drinks to drivers or provide alternatives to drinking and driving.

\subsection{Exposure to drunk driving campaign}

Exposure to alcohol related messages and anti-drunk driving campaigns may differ by sex, age, level and type of alcohol consumed among other factors. According to Lillard et al. (2018) drinkers, particularly young male drinkers, see much more anti-drunk driving advertising in the United States. Comparatively, younger men were said to have seen more advertisements concerning anti-drunk driving of all types than 
their female counterparts. This higher exposure is largely explained by sex differences in the propensity to read sports and adult magazines and to watch sports and gambling television programmes. Furthermore, Lewis et al., (2007) examined the third-person effect and its association with the extent male and female drivers reported intentions to adopt the recommendations of two road safety advertisements (antispeeding and anti-drunk driving) depicting high physical threats. A significant gender difference was observed with females reporting that messages from these advertisements would have more influence on them than others, while males reported that the messages would have more influence on others than on them. Furthermore, females reported higher intention not to speed and not to engage in alcohol impaired driving after being exposed than males.

However, Beck and Moser (2004) in a comparative study of drivers who were exposed to Maryland's sobriety "Checkpoint Strikeforce" campaign found that relatively few people $(9.6 \%)$ were exposed in any way to the campaign; however almost $30 \%$ were aware of it. Also, no differences were observed among those people who had been directly exposed to the campaign and those who were indirectly exposed. Exposure to the campaign was associated with increased perceptions of drink-driving risk, which was not dependent upon having personally experienced it.

On the level of exposure to communication campaigns on anti-drunk driving, Greenfield and Kaskutas (1998) in a study of a 5-year alcohol warning label messages and its contents in the US, noted that penetration was fairly high in target groups like heavier drinking younger adults. Exposure was predicted to rise to the asymptotic levels of $69 \%$ for male heavy drinkers and $65 \%$ for female heavy drinkers who saw the label in the initial 12 months. Analyses also showed that in all post- implementation years, maximum quantity consumed is an important predictor of exposure, as is younger age. Specific message exposure showed similar patterns as female drinkers aged 18-40 years remembered the pregnancy warning, while $38 \%$ of men aged $18-40$ years recall the drunk driving message.

Nevertheless, young people's exposure to anti-drunk driving campaign differs by country. Winpenny et al., (2012) discovered that adolescents in the UK and the Netherlands were more likely than adults to be exposed to alcohol advertising on television. While in Germany, adolescents had a lower exposure to alcohol adverts than adults. Similarly, young people in the UK (ages 10-15 years) and the Netherlands (13-19 years) were exposed to significantly more anti-drunk driving advertising compared to adults, than would be expected given their viewership patterns. In the UK, this age group was exposed to 11 percent more alcohol advertising than adults (aged 25 years and older). To this end, Evans-Whippet al., (2013) argued that exposure to others' drink driving during adolescence can be associated with an increased likelihood of DUI as a young adult. Therefore, strategies to reduce youth exposure to drink driving should be initiated.

\subsection{Level of agreement to DDD messages and issues of compliance with messages of road safety media campaigns}

Several studies showing the impact of anti-drunk driving campaigns on drivers and potential drivers exist. A systematic review of examining the role of social marketing programmes in preventing drunk driving was conducted. In the study, communication and program materials aimed at reducing drunk driving were identified and gathered from English-language websites from the USA, Canada, UK, Australia, and New Zealand. The review found that the social marketing programmes were effective in preventing drunk driving behaviours among the sample under study (Cismaru et al., 2009). While some researches show that such campaigns could be promising, others present a mix or contrary evidence. As an example, the Ontario Agency for Health Protection and Promotion (2015) found that media mediations have little impact on diminishing alcohol utilisation among women, youth and the overall public. However, the campaigns have been demonstrated to be viable in increasing alcohol related knowledge and awareness among women. Their examination equally showed computer or online interventions to be successful in decreasing drinking behaviour, especially among youth, high-hazard consumers, the overall public and students inside college and school settings.

Also, Lewis et al., (2008) revealed that females indicated more prominent goals not to drink and drive following their presentation to the negative appeals (i.e., the fear-evoking advertisements evoking feelings such as being 'afraid' and 'scared') with respect to their knowledge of the positive appeals (i.e., the humourous advertisements evoking feelings such as being 'amused' and 'happy) in the counter drinking promotions. Their findings suggested the existence of associations among key variables and proof of the more prominent persuasiveness of negative appeals following presentation with more prominent improvement of positive appeals after some time. Furthermore, Tay (2005) re-evaluated the effectiveness of the anti-drunk driving and anti-speeding enforcement and publicity campaigns implemented in the Australian State of Victoria which have thus far yielded mixed results in several evaluations. As opposed to previous evaluations, Tay examined the impacts of these campaigns on young male drivers who formed the primary target and examined the combined effects of the campaigns on the total number of serious crashes. Tay's study indicated that the anti-drunk driving enforcement and publicity campaigns had a significant independent effect in reducing crashes but their interactive effect was anti-complementary.

Glendon and Cernecca (2003) investigated young drivers' response to various types of messages attempting to influence drivers' behaviour to anti drink-driving and antispeeding messages in New Zealand. The authors found no differences between attitude-directed, behavior-directed, or attitude-and-behavior-directed messages in reducing reported speeding or drink-driving behavior intentions. The study also reported that respondents were more likely to say that they would reduce speeding than to reduce drinkdriving after viewing anti-speeding and anti-drunk-driving messages respectively. Also, while employing data elicited through a survey on a student sample at Lincoln University in New Zealand, Tay (2002) revealed that the anti-drunk driving campaign appeared to be successful in increasing the perceived apprehension and accident risks related to drunk driving and decreasing the intentions of the drivers to drink and drive. Regardless, as opposed to expectation, the campaign failed to elicit a stronger change in the target audience relative to the non-target audience. The study equally found partial evidence to support the publicity campaign. However, the study concluded that some refinements could be made to increase its efficacy among the target audience. In particular, the level of fear arousal should be moderated and the audience should be provided with effective and viable coping strategies to address the threat associated with drunk driving.

With regards to the empirical studies reviewed, it is very obvious that majority of the researches on exposure and compliance to anti-drunk driving messages were conducted in developed and industrialized countries and little of these studies were carried out in developing countries to which Nigeria belongs. Our study therefore examined motorists' exposure to FRSC's "Don't Drink and Drive" media campaign in Southeast, Nigeria and its effects on compliance levels. 


\section{METHODS}

\subsection{Sample}

The participants comprised of 266 (73.9\%) males and 94 (26.1\%) females. Participants were aged 18 and 60 years and above with those in the age brackets of $30-39$ years 116 (32.2\%) and 40 - 49 years 92 (25.6\%) respectively being the highest and hold Nigeria's valid drivers' license. The study was made up of 116 (32.2\%) commercial drivers and 244 (77.5\%) private drivers. The majority of participants (173 - 48.1\%) have being driving for 6 - 10 years as opposed to 16 (4.4\%) who reported to have been driving for over 20 years. Detail about the sample characteristics are shown in Table 1.

\begin{tabular}{|c|c|c|c|}
\hline Variables & $\begin{array}{c}\text { Sample } \\
\%,(n=360)\end{array}$ & $\begin{array}{c}\text { Exposed, } \\
\mathrm{n}=189\end{array}$ & $\begin{array}{c}\% \text { of Unexposed, } \\
\quad n=171\end{array}$ \\
\hline \multicolumn{4}{|l|}{ Gender } \\
\hline Male & 73.9 & 43.7 & 67.3 \\
\hline Female & 26.1 & 56.3 & 32.7 \\
\hline \multicolumn{4}{|l|}{ Age } \\
\hline$<20$ & 2.8 & 12.3 & 7.8 \\
\hline $20-29$ & 18.3 & 17.4 & 25.9 \\
\hline 30-39 & 32.2 & 23.2 & 30.0 \\
\hline $40-49$ & 25.6 & 25.0 & 12.0 \\
\hline 50-59 & 17.2 & 18.3 & 13.3 \\
\hline $60-69$ & 3.9 & 3.8 & 11.0 \\
\hline \multicolumn{4}{|l|}{ Marital status } \\
\hline Single & 29.2 & 3.3 & 13.9 \\
\hline Married & 67.8 & 34.0 & 12.4 \\
\hline Separated & 1.7 & 44.7 & 28.5 \\
\hline Widowed & 1.4 & 18.0 & 45.2 \\
\hline \multicolumn{4}{|l|}{ Education } \\
\hline No formal education & 2.5 & 3.0 & 12.1 \\
\hline Primary education & 3.9 & 12.4 & 44.5 \\
\hline Secondary education & 74.2 & 58.8 & 7.4 \\
\hline $\begin{array}{l}\text { Vocational/ } \\
\text { technical education }\end{array}$ & 13.9 & 10.9 & 12.5 \\
\hline Tertiary education & 5.6 & 14.9 & 23.5 \\
\hline \multicolumn{4}{|l|}{ Category of drivers } \\
\hline Commercial driver & 22.5 & 13.0 & 45.6 \\
\hline Private driver & 77.5 & 87.0 & 54.4 \\
\hline \multicolumn{4}{|l|}{ Income (Nigerian } \\
\hline \multicolumn{4}{|l|}{ Naira) } \\
\hline$<20,000$ & 7.2 & 33.2 & 56.4 \\
\hline $20,000-65,000$ & 60.3 & 34.3 & 23.5 \\
\hline 65,001 and above & 32.5 & 32.5 & 20.1 \\
\hline \multicolumn{4}{|l|}{$\begin{array}{l}\text { Number of years } \\
\text { spent as a driver }\end{array}$} \\
\hline $0-5$ & 20.3 & 13.5. & 16.9 \\
\hline $6-10$ & 48.1 & 18.3 & 21.2 \\
\hline $11-15$ & 19.7 & 21.4 & 15.8 \\
\hline $16-20$ & 7.5 & 19.6 & 28.8 \\
\hline Above 20 & 4.4 & 27.2 & 17.3 \\
\hline
\end{tabular}

Table 1. Sample characteristics for Exposed and Unexposed Drivers

\subsection{Procedure}

A descriptive survey was used to elicit information from selected participants. The study involved 360 registered commercial and private drivers in three selected states (Anambra, Ebonyi and Enugu) in South-eastern region of Nigeria. The choice of the South-eastern Nigeria was based on the fact that there is a high level of alcohol consumption in the region. According to Adebowale (2019) the Southeastern region of Nigeria in 2016, spent 44 billion naira $(118,791,508$ USD) on alcohol consumption, making her the second highest region with alcohol consumers in Nigeria.
The study adopted a multistage sampling approach. At the first stage, we used a simple random sampling technique to select three states from the five states in the region. At the second stage, we used a purposive sampling to select two urban centres in each of the states selected. In Anambra, Awka and Onitsha were selected. In Enugu, Enugu and Nsukka were selected. Finally, Abakaliki and Afikpo were selected in Ebonyi. Furthermore, we began the next stage by randomly selecting car packs, residential areas and centre business districts. From the areas that were selected, the research team adopted a convenience sampling technique to approach the drivers. Copies of the questionnaire were administered with the help of two research assistants who were recruited from the University of Nigeria, Nsukka campus and trained intensively for one week on how to carry out the exercise. Questionnaire administration became possible after respondents met the following inclusion criteria: (1) presented evidence that they had obtained a provisional drivers' licence or showed a valid drivers' license; (2) affirmed that they are resident of the states, (3) admitted to have taken alcohol in the past and (4) indicated willingness to participate in the study. Before the study was conducted, the researcher obtained an ethical clearance from the Health Research Ethics Committee (HREC) which is the institutional review body domicile at the University of Nigeria Teaching Hospital, Ituku-Ozalla, Enugu. The committee reviewed and approved the study before the seeking of verbal consent from the study participants.

\subsection{Materials and Measures}

This study is part of a larger project examining the impact of DDD campaigns on motorists' and susceptibility to road traffic accident arising from drunk driving. The overview of the present study comprised of two segments: (a) demographic characteristics and other key questions that informed the study. Exposure to the DDD campaign was measured by a five item scale. The first item was worded "To what extent are you exposed to DDD safety campaign in the past six months". Other examples out of the items read: "To what extent did you come across the DDD messages on electronic media (e.g., Facebook, Internet, etc) in the past six months?" and "To what extent did you encounter FRSC and BSG officials distribute fliers about DDD in the past six months?". We observed a highly reliable Cronbach's alpha $(\alpha)$ of .83 for the scale. Response options ranged from "a very large extent" to "a very low extent". This was on a 4 point scale. Cumulatively, those who answered "a very large extent" and "moderate extent" were defined as personally exposed $(\mathrm{N}=189)$. On the other hand, motorists/drivers who answered "to a low extent" and "a very low extent" were defined as personally unexposed to the DDD campaign ( $\mathrm{N}=171)$. Nevertheless, non-exposure does not necessarily mean that drivers are not totally unexposed or unaware of the central theme of the DDD campaign (e.g., 'don't drink and drive', and 'stay alive, etc.), it suggests that they had heard the campaign from any of the media sources to "a low extent" or "very low extent".

Agreement (i.e., credibility of the content ) with the messages of the "Don't Drink and Drive" campaign was further measured by a 12-item, 4-point Likert scale, ranging from "Strongly Agree", "Agree", "Disagree" and "Strongly Disagree". For example, the first item was worded, "Stay alive and stop drunk driving". Among the rest of the items, the second item was worded, "When you drink let someone else drive". While certain items were positively worded, others were negatively word. Scores from negatively worded items were reversed (such that high agreement would suggest a low credibility for the content of the negatively worded item) before analysis was performed on them. A reliable Cronbach's alpha $(\alpha)$ of .71 was obtained for the scale. The motorists/drivers' self- 
report compliance to the DDD behaviour was measured by eight items. The first item (the rest are shown in Table 2) was worded "I avoid alcohol especially whenever am to drive". Response options for all the items ranged from "Strongly Agree", "Agree", "Disagree" and "Strongly Disagree". We obtained a reliable Cronbach's alpha ( ) score of .82 for the scale. All segment of the scales used were reliable. Researchers (Ale, 2020; Olijo, 2020; Ogbonne, 2019) say that reliability figure of above .70 is excellent.

\subsection{Analysis}

Data were analysed using SPSS version 23.0. An independent-samples t-test was conducted to compare the extent of exposure to "Don't Drink and Drive" (DDD) campaign across gender category. A one-way between-groups analysis of variance (ANOVA) was performed to explore the impact of sample characteristics on the extent of exposure to DDD campaign. A chi-square test for odd ratio (OR) and relative risks (RR) was performed to ascertain the level of compliance to "Don't Drink and Drive" campaign among motorists who were exposed and unexposed to the campaign. Also, an independent-samples t-test was conducted to compare the extent of agreement to the "Don't Drink and Drive" (DDD) messages across motorists who were exposed and unexposed to the campaign.

\subsection{Result}

01. Level of exposure to "Don't Drink and Drive" campaign across motorists' sample characteristics

An independent-samples t-test was conducted to compare the extent of exposure to "Don't Drink and Drive" (DDD) campaign for both males and females. There was no significant difference in scores for both males $(M=3.23, S D=.81)$ and females $[M=3.26, S D=.76 ; t(358)=.23, p=.82]$. The magnitude of the difference in the means was very small (eta squared $=.00014$ ).
Furthermore, a one-way between-groups analysis of variance was performed to explore the impact of sample characteristics on the extent of exposure to DDD campaign. Respondents were divided into 6 groups according to their age (as shown in Table 1). There was a statistically significant difference in the extent of exposure to DDD campaign across the age groups $[F=(5,354)=3.1, p=.01]$. Although it reached statistical significance, the actual difference between the means scores was small with an effect size of .001. Post-hoc comparison using the Tukey HSD test showed that the mean score for respondents between 20-29 years $(M=2.97, S D=1.12)$ was significantly different from respondents between 30-39 years $(M=3.41, S D=.69)$. Respondents who are less than 20 years $(M=3.40, S D=.97)$, $40-49$ years $(M=3.20, S D=.70), 50-59$ $(M=3.19, S D=.62)$ years, $60-69$ years $(M=3.50, S D=.65)$ did not differ significantly from either respondents between 20-29 years and 30-39 years. This finding indicates that age has an influence on exposure to these DDD messages.

We also compared the means of respondents in the extent of their exposure to DDD campaign across educational categories. There was a statistically significant difference in their extent of exposure to the campaign $[F=(4,355)=2.8, \mathrm{p}=.03]$, with respondents who have primary education $(M=2.79$, $S D=.58)$ differing statistically from those with vocational/ technical education $(M=3.50, S D=.76)$. Meanwhile, respondents with no formal education $(M=3.44, S D=.53)$, secondary education $(M=3.15, S D=.59)$ and tertiary education $(M=3.21$, $S D=.82$ ) did not differ significantly from those with primary education and vocational/technical education. A small effect size (.03) was obtained.

We also obtained a statistically significant difference in the scores of respondents' extent of exposure to the DDD campaigns across income categories $[F=(2,357)=23.7$, $\mathrm{p}=.000]$. The group who earn less than $\mathrm{N} 20,000(M=2.31$, $S D=1.3$ ) was significantly different from the groups who earn

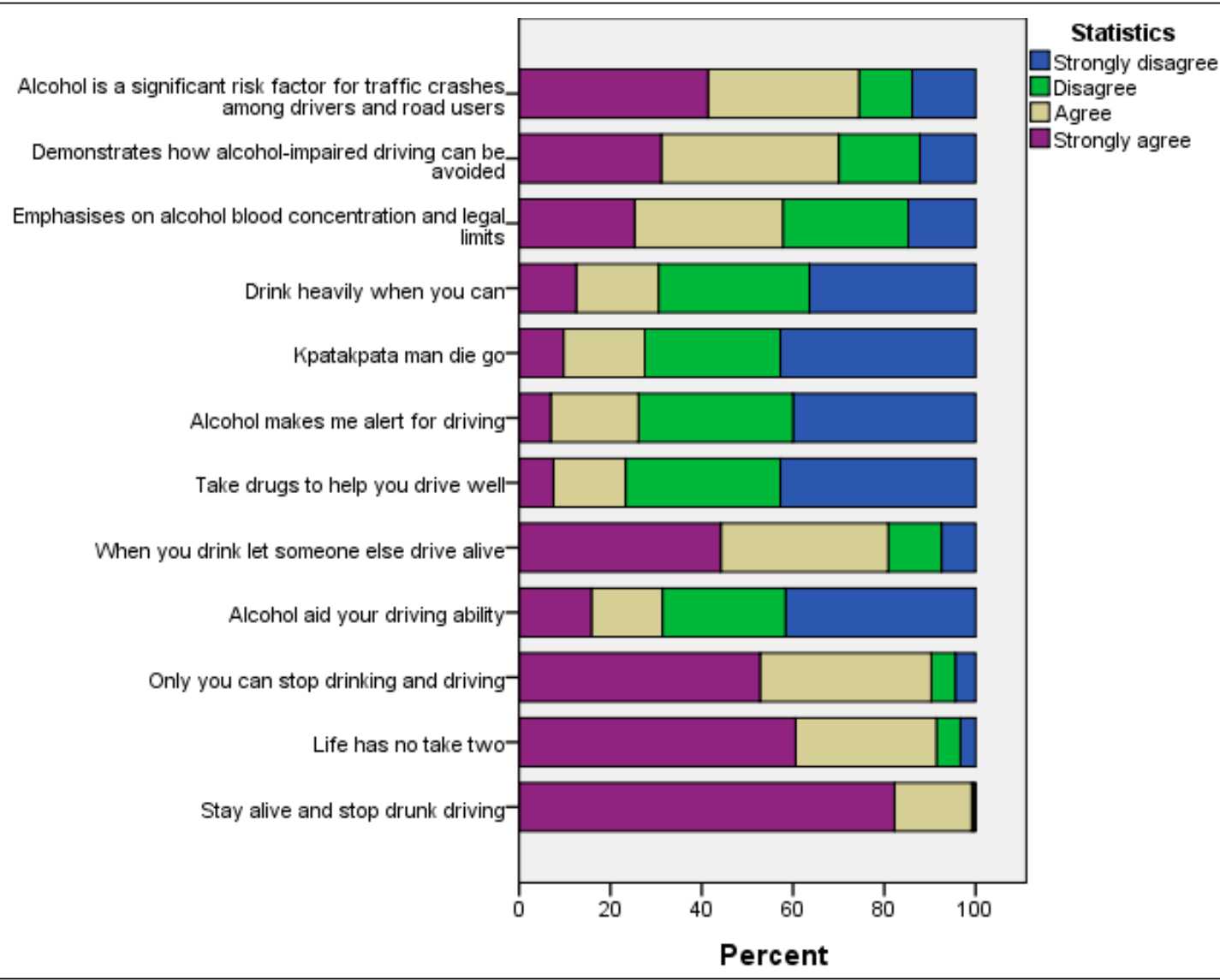

Figure 1. Stacked bar chart showing proportion of motorists' level of agreement with the "Don't Drink and Drive" campaign in South-east Nigeria 
between N20,000-N65,000 ( $M=3.25, S D=.70)$ and N65,001 and above $(M=3.43, S D=.69)$. However, those who earn between N20,000-N65,000 did not differ significantly from those who earn between N65,001. A medium effect size (.11) was equally obtained.

We finally analysed the impact of number of years respondents spent as a driver on extent of exposure to DDD campaigns. The result showed that there was a statistically significant difference in the extent of exposure $[F=(4,355)=8.0$, $\mathrm{p}=.000]$. Respondents who have been driving between $0-5$ years $(M=2.86, S D=1.02)$ differ significantly from respondents who have spent $6-10$ years $(M=3.25, S D=.68), 11-15$ years $(M=3.37, S D=.78), 16-20$ years $(M=3.52, S D=.64)$ and above 20 years $(M=3.81, S D=.40)$ driving. Those who have spent 6-10 years driving did not differ significantly from others who have spent $11-15$ years and 16-20 years. The actual difference in the mean scores between the groups was medium. The effect size using eta squared was .02. There were no differences in exposure across marital status and category of drivers.

02. Motorists' level of agreement with regards to the "Don't Drink and Drive" campaign in South-east Nigeria

According to the information in Figure 1, motorists/drivers showed a high level of agreement with the contents of the DDD campaign. For example, they mostly posited that DDD campaign presented alcohol as significant risk factor for traffic accidents among drivers and road users. Many also believed that the campaign was about staying alive and stopping drunk driving. For items that were negatively worded (such as kpatakpata man go die i.e., a death resulting from drunk driving is as predetermined as a natural death), most respondents disagreed that the campaign contained messages that encouraged heavy drinking. There was a consistency in the pattern of answers obtained, with many of the participants who agreed with the positively worded items, disagreeing with the negatively worded items. As a result, the finding suggests that the level of agreement with the contents of the DDD campaign was high among motorists interviewed.

03. The impact of "Don't Drink and Drive" campaigns on motorists' level of agreement with the content of the messages An independent-samples t-test was performed to compare the motorists' agreement level concerning the "Don't Drink and Drive" (DDD) campaign for both exposed and unexposed drivers. Finding indicates that there was no significant difference in scores for both exposed $(M=32.14, S D=5.53)$ and unexposed drivers $[M=32.53, S D=5.25 ; t(358)=.683, p=.49]$. The magnitude of the difference in the means was very small (eta squared=.0013). The result suggests that drivers' exposure to DDD campaign does not impact on their agreement level with regards to the specific contents of the DDD campaign.

O4.Level of self-reported compliance to "Don't Drink and Drive" campaign among motorists who were exposed and unexposed to the campaign

According to the information in Table 2, exposed drivers $(49.7 \%)$ were less likely, with an odd ratio of .637 to avoid alcohol especially when they are about to drive than unexposed drivers (60.8\%). However, exposed drivers (55.0\%) were 1.8 times more likely to reduce alcohol intake at other times than unexposed drivers (40.4\%). Educating others on the dangers of drunk driving was more of the responsibility of exposed drivers (49.2\%) than unexposed drivers (35.1\%), with the exposed drivers having 1.79 likelihood of educating other drivers than the unexposed. Furthermore, the odds of reporting drunk drivers (1.0) were the same for exposed (27.5\%) and unexposed (27.5\%) drivers. Equally, the odd of changing alcohol consumption pattern to suit driving without drinking is 1.29 times greater for exposed drivers (65.1\%) compared to unexposed drivers (59.1\%). Unexposed drivers (51.5\%) were .88 times more likely to surround themselves with people who are alcohol free than exposed drivers (46.6\%). The odds of joining a support group who cheer and motivate drivers to stay away from alcohol is 1.4 times greater for exposed drivers (58.7\%) compared to unexposed drivers (49.7\%). Finally, exposed drivers (46.6\%) were more likely to avoid keeping alcohol in the car or in the house than unexposed drivers (42.7\%). The likelihood for this behaviour was 1.7 times greater. Furthermore, we observed that differences between the exposed and unexposed drivers across the first three items on the self-reported compliance scale (as shown in Table 2) reached statistical significance. For example, we found that those exposed to the DDD campaign were less likely to avoid alcohol when driving compared to those who were exposed. This is an indication of the campaign effectiveness in targeting drivers who were more likely to indulge in drunk driving. In like manner, result revealed that drivers who were exposed to the DDD messages had higher odds to reduce alcohol intake at other times. This also suggests that the campaign was effective in targeting drivers who were more likely to be drinking and driving. Lastly, we found that those exposed to the campaign were more likely to educate others on the dangers of drunk-driving. This further highlights the DDD campaign's effectiveness

Self-reported Compliance to the DDD campaigns

\section{Exposure to DDD campaign}

\begin{tabular}{|c|c|c|c|c|c|}
\hline & $\begin{array}{l}\text { Exposed, } \\
\mathrm{n}=189\end{array}$ & $\begin{array}{c}\text { Unexposed, } \\
\text { unexposed, } \mathrm{n}=171\end{array}$ & OR, CI & $\begin{array}{l}\mathrm{RR}, \mathrm{CI} \text { for the } \\
\text { exposed drivers }\end{array}$ & $\begin{array}{l}\mathrm{RR}, \mathrm{CI} \text { for the } \\
\text { unexposed drivers }\end{array}$ \\
\hline I avoid alcohol especially whenever am to drive & $94(49.7 \%)$ & $104(60.8 \%)$ & $.637, .419-.968$ & $.818, .678-.986$ & $1.283,1.02-1.62$ \\
\hline I reduce alcohol intake at other times & $104(55.0 \%)$ & $69(40.4 \%)$ & $1.81,1.19-2.75$ & $1.36,1.09-1.71$ & $.754, .617-.921$ \\
\hline I educate others on the dangers of drunk-driving & $93(49.2 \%)$ & $60(35.1 \%)$ & $1.79,1.17-2.74$ & $1.40,1.09-1.80$ & $.782, .655-.935$ \\
\hline $\begin{array}{l}\text { I change my alcohol consumption pattern to suit } \\
\text { driving without drinking }\end{array}$ & $123(65.1 \%)$ & $101(59.1 \%)$ & $1.29, .843-1.98$ & $1.10,936-1.30$ & $.853, .654-1.11$ \\
\hline I report drunk drivers & $52(27.5 \%)$ & $47(27.5 \%)$ & $1.00, .630-1.59$ & $1.00, .715-1.40$ & $1.00, .880-1.14$ \\
\hline I surround myself with people who are alcohol free & $88(46.6 \%)$ & $88(51.5 \%)$ & $.882, .543-1.24$ & $.905, .733-1.12$ & $1.10, .898-1.35$ \\
\hline $\begin{array}{l}\text { I join a support group who cheer and motivate } \\
\text { me to stay away from alcohol }\end{array}$ & $111(58.7 \%)$ & $85(49.7 \%)$ & $1.44, .949-2.18$ & $1.18, .975-1.43$ & $.821, .655-1.03$ \\
\hline I avoid keeping alcohol in the car or in the house & $88(46.6 \%)$ & $73(42.7 \%)$ & $1.17, .771-1.77$ & $1.091, .865-1.374$ & $.932, .775-1.12$ \\
\hline
\end{tabular}

Exposed to DDD campaign vs. unexposed to the campaign.OR,oddsratio;RR, relative risk of being exposed versus unexposed for group who complied vs. group who did not comply to the DDD campaigns; CI,95\% con dence interval

Table 2.Self-reported Compliance to "Don't Drink and Drive" campaign in South-east Nigeria among motorists who were exposed and those unexposed to the campaign 
in reaching the higher risk drivers who are the major target of the programme.

\section{DISCUSSION}

The major objective of the study was to examine motorists' exposure and compliance to FRSC's and BSG (Beer Sectoral Group) "Don't Drink and Drive" media campaign in Southeast, Nigeria. First, findings revealed that there was no significant difference in scores for both males $(M=3.23, S D=.81)$ and females $[M=3.26, S D=.76 ; t(358)=.23, p=.82]$, suggesting that male drivers were similar to their female counterparts in their pattern of exposure to the DDD messages. A related indifference was noticed in the study of Jones et al. (2017). Put together, such findings might indicate that there is a sort of gender equality in transport practice with regards to accessing information or media messages that could instil responsible driving behaviours among drivers. Nonetheless, a look at the mean score indicates that women scored slightly higher on the extent of exposure to the DDD campaign compared to the males. This slight (and statistically insignificant) gender difference has been highlighted in similar studies suggesting that females were more willing to accept such messages. For example, Lewis et al. (2007) reported that females were more likely to identify the benefits of road safety advertising on themselves than their male counterparts across an Australian sample. In contrast, studies by (Lillardet al., 2018; Beck $\&$ Moser, 2004) found that young male drinkers have seen much more alcohol advertising than their female counterparts. However, this little or no difference in exposure (going by the gender mean scores) between the male and female drivers in our study may be attributed to the location/region of the country where the study is carried out, in that there is no gender restriction in driving in the area.Our finding therefore suggests that putting in to perspective, a situation where both male and female drivers' interests form the basis of intervention is salient (since they can both be in the high risk group).

Findings also revealed that age was a significant determinant factor of exposure to DDD campaign, although drivers who are less than 20 years, 40-49 years, 50-59 years, and 60-69 years did not differ significantly from those between 20-29 years and 30-39 years. However, drivers aged 20-29 years were significantly different from those between 30-39 years, even though the difference was not practically relevant. Altogether, the drivers at early adulthood scored lower in their extent of exposure compared with teenaged and senior drivers. More specifically, exposure was lower for 20-29 year-olds $(M=2.97, S D=1.12)$ than 30 -39 year-olds $(M=3.41$, $S D=69$ ), and other younger and older age groups. As a result, this outcome could be pointing at an important age category that should be of interest in anti-drunk driving intervention efforts. Several studies have specified a target age group (ranging from 15-34 years) for their media campaigns for reducing alcohol impaired driving (e.g., Murry, et al., 1993; National Highway Traffic Safety Administration, 2007; Whittam, et al., 2006). These target age categories fit into the age group with the least DDD campaign exposure in our study. This outcome has enormous implication for age specific road safety intervention. Furthermore, this finding that age has an influence on exposure to these messages is related to previous research (e.g., Gotthoffer, 2001; Winpennyet al., 2012). Additionally, it is obvious from our result that those in the higher age category had more exposure than those in the lower age category (except for the teenagers who constitute the lowest proportion of drivers in both our sample and the study area). The findings from a similar study by Winpennyet al. (2012) revealed that, in Germany, respondents aged 4-9 years were exposed to significantly fewer alcohol adverts than adults aged 25+, with very small effect sizes (IRRs: $0.96,0.95$ and 0.94 respectively). Consequently, our findings extend previous literature by showing how differences in age can inform explanations in to how drivers get exposure to DDD campaigns. The knowledge of these differences could also contribute to anti-drunk-driving intervention designs that focus more on younger drivers. By understanding this dynamics, policy makers in this area might begin to create age focus interventions to increase traffic education and awareness.

Our finding also indicated that education might be a factor to consider in exposure to DDD messages in our sample. Similar studies have focused on educational inequality and the understanding of anti-drunk driving campaigns (Jones et al., 2017; Regan \& Mitsopoulos, 2001). For example, in their study, Jones et al. (2017) reported that important differences exist in the interpretation of anti-drunk driving messages by level of educational attainment of respondents. Such educational peculiarities might have played a role in the direction with which our samples got exposed to the messages. In our findings, those with vocational/technical education, followed by those with no formal education had the highest mean scores in their exposure to the DDD campaigns. Plausible explanation for these high scores among these groups of educational category might be that driving as an activity or profession does not involve formal educational certification and therefore exposure to such DDD messages might just be a function of individual interests. This is coupled with the fact that such messages are often passed in local languages (usually in Pidgin English). While we understand that differences in exposure to DDD messages across education categories reached statistical significance, there was overall a small effect size as determined by eta squared.

Our result suggests that drivers' with lower income are less likely to be exposed to the DDD campaigns when compared with drivers with higher income. Specifically, those who earned less than N20,000 had a the lowest mean score with respect to the extent of their exposure. As a result, intervention and policy initiatives that focus on the lower income group of drivers is needed to address the finance related problems as well as increase access to the messages of the campaign.

Equally, we found that motorists with lesser number of years of driving scored lower compared with those with higher number of years of driving in their exposure to the DDD campaigns. This means that drivers who are well experienced (i.e., who have been driving for a long time) might be more inclined to be exposed to DDD campaigns than those with less experience. A further look at the differences in the means scores showed a continuous increment in the exposure scores as the number of years spent driving increases. This finding is related to a similar research showing the effects of driving experience on traffic accident risks among intoxicated drivers in a Chinese city (Cheng et al., 2019). According to the authors, drivers with $\leq 2$ years of driving experience will be more inclined to cause a traffic accident compared with the experienced drivers. As a result, our findings extends the literature on how driving experience and skills (measured by the number of years) can possibly be an influence on how drivers chose to be exposed to media messages that encourages responsible driving behaviour.

The finding of this study showed that level of agreement with the contents of the DDD campaign was high among motorists interviewed. This was so because the majority of the respondents strongly agreed that alcohol is a significant risk factor for traffic accidents among drivers and road users. Also, they believed that the campaign was about staying alive and stopping drunk driving. This result is in consonance with Dangana et al., (2017) who reported that (98.5\%) respond- 
ents in their study were very much aware of and educated about substance abuse, as they were exposed to messages on substance abuse through their student support programme. Ontario Agency for Health Protection and Promotion (2015) also supports the present study, as they observed that media mediations have little impact on diminishing alcohol utilisation among women, youth and the overall public, however have been demonstrated to be viable in increasing alcohol related exposure and attitude among women.

Finding also indicated that there was no significant difference in scores for both exposed and unexposed drivers in respect to their level of agreement with content of the campaign. Therefore, drivers' level of exposure to DDD campaign does not have an impact on their level of agreement to the contents of DDD campaign. This result is consistent with Beck and Moser (2004) where it was observed that there was no difference among those people who had been directly exposed to the Maryland Sobriety campaign and those who were indirectly exposed. Plausible explanation for this finding could be that some of the drivers in our sample (i.e., those who were unexposed to the campaigns) might have already known about the dangers of drunk driving through other means; such that their high level of agreement with the content of the DDD campaigns happened to be a coincidence.

Furthermore, there were significant differences in selfreported compliance, particularly across the first three items (i.e., likelihood of avoiding alcohol when driving, reducing alcohol intake at other times and the likelihood to educate others on the danger of drunk driving) in Table 2. This is an indication of the effectiveness of the DDD campaign towards the group of drivers who might have a higher tendency to drink and drive. Studies showing the potential effectiveness of similar campaigns in different climes (e,g,, Canada, Australia, etc) outside Nigeria abound (e.g., Dangana et al., 2017; Lewis et al., 2007; Lewis et al., 2008; Ontario Agency for Health Protection and Promotion, 2015). Even though some of these campaigns were only directed at alcohol abuse, our findings confirmed that anti-drunk driving campaigns could be effective in increasing exposure as well as compliance to the contents of these messages in different environment and by extension affect the behaviour of drivers while behind the wheels. While we understand that majority of the available literature focusing on anti-drunk driving campaigns are situated within the Western industrialized context, our findings extend knowledge on the subject of study by showing the potential efficacy of a similar campaign in an entirely different social and physical space (i.e., a developing society like Nigeria).

\section{CONCLUSION}

The study examined motorists' exposure to FRSC's and BSG's "Don't Drink and Drive" media campaign in South-east, Nigeria and its effects on compliance levels. Based on the findings of the study, there is evidence to suggest that the DDD campaigns might have a significant impact on the likelihood of avoiding alcohol when driving, reducing alcohol intake at other times and educating others on the danger of drunk driving. We also believe that the campaigns might be more effective when policy designers and interventionists concerned with road safety begin to focus on the differences in the demographic characteristics of the drivers. Although the thoughts of majority of the drivers sampled were consistent with what DDD campaign preaches in the South-east region of Nigeria, we believe that there are still some drivers (as shown in our sample) who are not only unexposed to these messages but also do not agree with the messages of the anti-drunk driving messages. While we advise that the intervention should continue alongside the use of legal back-up (i.e., by imposing some sanctions on drunk drivers) for optimal performance, the campaign efforts should factor in the roles of multiple variables that have been raised in this study. Raising consciousness and or susceptibility towards road traffic accidents might also be seen as an advantage which should be capitalized on. In other words, we believe that when drivers are made to think of the potential risks of engaging in drunk-driving behaviours, they might likely reconsider their stance and change for the better.

\section{Limitations and future research directions}

The present study has been limited to participants predominantly selected from a particular region in Nigeria. Also, the small sample size was seen as a limitation. These could impact on the generalizability of the findings. To address this limitation, we included randomisation in sample selection at various steps (excluding the last stage of selection where a convenient sampling was used) during the research. Nevertheless, we suggest that similar studies should be carried out across other regions of the country. While we understand that the lack of drivers' registry or list in the region could sometimes make direct selection of drivers impossible, future studies could collaborate with the state drivers' union and the road safety corps to supply them with a list of drivers.

\section{Declaration of conflicting interests}

The author(s) declared no potential conflicts of interest with respect to the research, authorship, and/or publication of this article.

\section{Funding}

The author(s) received no financial support for the research, authorship, and/or publication of this article.

\section{REFERENCES}

Adebowale, A. (2019). South-south leads Nigeria's huge alcohol consumption, NBS data shows. Retrieved from www.premiumtimes.com

Adejugbagbe, A. M., Fatiregun, A. A., Rukewe, A., \& Alonge, T. (2015). Epidemiology of road traffic accidents among long distance drivers in Ibadan, Nigeria. African Health sciences, 15(2), 480-488.

African Development bank Group (2013). Road Safety in Africa Assessment of Progresses and Challenges in Road Safety Management System. Retrieved from https://www.afdb. org/fileadmin/uploads/afdb/Documents/Events/ATFforum/ Road_Safety_in_Africa_-_Assesement_of_Progresses_and Challenges in Road_Safety_-_AfDB.pdf

Akintude, A. A., Adeniran, J., Akintunde, T. S., Oloyede, T. O., Salawu, A. A., Oladipo, O. G. (2019). Air quality index and cardiovascular risk factors among automobile technicians in Southwest Nigeria. Nigerian Journal of Cardiology, 16, 32-37.

Ale, V. (2020). A library-based model for explaining informationexchange on Coronavirus disease in Nigeria. Ianna Journal ofInterdisciplinary Studies, 2,1-10.0000000000000

Al-Taweel, H. M., Young, W., \& Sobhani, A. (2016). A binary logistic regression model of the driver avoidance manoeuvers in two passenger vehicle crashes. Australasian Transport Research Forum 2016 Proceedings 16th and 18th November, Melbourne, Australia.

Assailly, J., \& Cestac, J. (2018). Drunk driving prevention and cultural influences: the SAFE ROADS 4 YOUTH (SR4Y) project. Transactions on Transport Sciences, 9(2), 35-41.

Asemah, E. S., \& Omosotomhe, S. I. (2016). Self-affirmative discourse on fear appeals as a strategy for effective road safety campaigns in Nigeria. JORIND 14:2 Retrieved from www.transcampus.org/ journal; www.ajol.info/journals/jorind. Pg. 1-7 
Astrøma, A. N., Moshiro, C., Hemed, Y., Heuchd, I., \& Kvale, G. (2006). Perceived susceptibility to and perceived causes of road traffic injuries in an urban and rural area of Tanzania. Accident Analysis and Prevention (38) 54-62

Atubi, A. O., \& Gbadamosi, K. T. (2015). Global positioning and socio-economic impact of road traffic accidents in Nigeria: matters arising. American International Journal Contemporary Research, 5(5), 136-146.

Bachani, A. M., Risko, C. B., Gnim, C., Coelho, S., \&Hyder, A. A. (2017). Knowledge, attitudes, and practices around drinking and driving in Cambodia: 2010-2012. Public health, 144, S32-S38.

Beck, K. H., \& Moser, M. L. (2004) Exposure to the Sobriety "Checkpoint Strikeforce" Campaign in Maryland: Impact on Driver Perceptions of Vulnerability and Behaviour. Traffic Injury Prevention, 5:2, 101-106, DOI:10.1080/15389580490434908

Bennett, L. A., Campillo, C., Chandrashekar, C. R., \& Gureje, O. (1998). Alcoholic beverage consumption in India, Mexico, and Nigeria: a cross-cultural comparison. Alcohol Health Res World, 22, 243-252.

Blows, S., Ivers, R. Q., Connor, J., Ameratunga, S., \& Norton, R. (2003). Car insurance and the risk of car crash injury. Accident Analysis \& Prevention, 35(6), 987-990. doi:10.1016/s00014575(02)00106-9

Blows, S., Ivers, R. Q., Connor, J., Ameratunga, S., Woodward, M., \& Norton, R. (2005). Unlicensed Drivers and Car Crash Injury. Traffic Injury Prevention, 6(3), 230-234. doi:10.1080/15389580590969175

Özkan, T., Lajunen, T., Chliaoutakis, J. E., Parker, D., \& Summala, H. (2006). Cross-cultural differences in driving behaviours: A comparison of six countries. Transportation Research Part F: Traffic Psychology and Behaviour, 9(3), 227-242. doi:10.1016/j. trf.2006.01.002

Cheng, Z., Zu, Z., Lu, J., \& Li. Y. (2019). Exploring the effect of driving factors on traffic crash risk among intoxicated drivers: A case study in Wujiang. International Journal of Environmental Research and Public Health, 16(14), 2540. doi:10.3390/ ijerph 16142540

Cismaru, M., Lavack, A. M., \& Markewich, E. (2009). Social marketing campaigns aimed at preventing drunk driving. International Marketing Review, 26(3), 292-311. doi:10.1108/02651330910960799

Damsere-Derry, J., Palk, G., \& King, M. (2016). Motorists' knowledge, attitudes and practices towards alcohol-impaired driving/riding in Ghana. Traffic Injury Prevention, DOI: 10.1080/15389588.2016.1193172

Damsere-Derry, J., Palk, G., \& King, M. (2017). Road accident fatality risks for "vulnerable" versus "protected" road users in northern Ghana. Traffic Injury Prevention. DOI: 10.1080/15389588.2017.1302083

Dangana, J. M., Ogunsanmi, O., Makinde, B., Omozusi, M., Olaoye, T., Ezeokoli, R., \& Sifon, V. (2017). The benefits of students' support follow-up program on students involved in substance abuse: Empirical evidence from Babcock University Community. IOSR Journal of Humanities and Social Science (IOSR-JHSS) (22)10, PP 09-14

Elder, R. W., Shults, R. A., Sleet, D. A., Nichols, J. L., Thompson, R. S., Rajab, W., \& Task Force on Community Preventive Services. (2004). Effectiveness of mass media campaigns for reducing drinking and driving and alcoholinvolved crashes: a systematic review. American Journal of Preventive Medicine, 27(1), 57-65.

Epperlein, T. (1987). Initial deterrent effects of the crackdown on drinking drivers in the state of Arizona. Accid Anal Prev. 9, 285-303.

Evans-Whippa, T. J., Plentya, S. M., Toumbouroua, J. W., Olssona, C., Rowland, B., \& Hemphilld, S. A. (2013). Adolescent exposures to drink driving as a predictor of young adults' drink driving. Accident Anal Prev. 51: 185-191. doi:10.1016/j. aap.2012.11.016.
Ezemalu, B. (2013, December). Eight in ten Nigerian drivers drive under the influence of alcohol, study says. Retrieved from https://www.premiumtimesng.com/news/151678-eight-tennigerian-drivers-drive-influence-alcohol-study-says.html

Glendon, A. I., \& Cernecca, L. (2003). Young drivers' responses to anti-speeding and anti-drunk-driving messages. Transportation Research Part F: Traffic Psychology and Behaviour, 6(3), 197-216. doi:10.1016/s1369-8478(03)00026-3

Gotthoffer, A. R. (2001). Exploring the relevance of localization in anti-drinking and driving PSAs. Health Marketing Quarterly, 18(3-4), 63-79. doi:10.1300/j026v18n03_06

Greenfield, T. K., \& Kaskutas, L. A. (1998). Five years' exposure to alcohol warning label messages and their impacts: Evidence from diffusion analysis. Applied Behavioural Science Review, 6, (1), 39-68.

Guo, F., Klauer, S. G., Fang, Y., Hankey, J. M., Antin, J. F., Perez, M. A., ... Dingus, T. A. (2016). The effects of age on crash risk associated with driver distraction. International Journal of Epidemiology, dyw234. doi:10.1093/ije/dyw234

Hazen, A., \& Ehiri, J.E. (2006). Road Traffic Injuries: Hidden Epidemic in Less Developed Countries. Journal of the National Medical Association, 98, 73-82.

Horwood, L. J., \& Fergusson, D. M. (2000). Drink driving and traffic accidents in young people. Accident Analysis and Prevention, $32,805-814$

Impinen, A., Mäkelä, P., Karjalainen, K., Haukka, J., Lintonen, T., Lillsunde, P., Rahkonen, O., \& Ostamo, A. (2011).The association between social determinants and drunken driving: A 15-year register-based study of 81,125 suspects. Alcohol and Alcoholism Vol. 46, No. 6, pp. 721-728

International Alliance for Responsible Drinking [IARD], (2020). In 2010, the World Health Organization (WHO) adopted its "Global strategy to reduce the harmful use of alcohol" 1 and the United Nations General Assembly (UNGA) announced its "Decade of Action for Road Safety 2011- 2020" 2 ; both emphasized the importance of reducing drink driving. Retrieved from https://iard.org/getattachment/d16e1b1d-4d2c-4579-9845d37f4597ad7c/c4-drink-driving.pdf

Jones, S. C., Hall, S., \& Kypri, K. (2017). Should I drink responsibly, safely or properly? Confusing messages about reducing alcoholrelated harm. PLOS ONE, 12(9), e0184705. doi:10.1371/journal. pone. 0184705

Keatley, D. A., Barsky, A. D., \& Clarke, D. D. (2016). Driving under the influence of alcohol: A sequence analysis approach. Psychology, Crime \& Law, DOI:10.1080/106831 6X.2016.1228933

Lewis, I., Watson, B., \& Tay, R. (2007). Examining the effectiveness of physical threats in road safety advertising: The role of the third-person effect, gender, and age. Transportation Research Part F 10, 48-60

Lewis, I., Watson, B., \& White, K. M. (2008). An examination of message-relevant affect in road safety messages: Should road safety advertisements aim to make us feel good or bad? Transportation research part F: traffic psychology and behaviour, 11(6), 403-417.

Lillard, D. R., Molloy, E., \& Zan, H. (2018). Television and magazine alcohol advertising: exposure and trends by sex and age. Journal ofStudies of Alcohol and Drugs, 79, 881-892.

Males, M. A. (2009). Poverty as a determinant of young drivers' fatal crash risks. Journal of Safety Research, 40(6), 443-448. doi:10.1016/j.jsr.2009.10.001

McLean, A. J., Kloeden, C. N., \& McCaul, K. A. (1989). Drinkdriving in the general night time driving population, Adelaide. Aust J Public Health, 15, 190-3.

Mock, C., Quansah, R., Addae-Mensah, L., \& Donkor, P. (2005). The development of continuing education for trauma care in an African nation. Injury, 36(6), 725-732.

Murry, J. P., Stam, A., \& Lastovicka, J. L. (1993). Evaluating an AntiDrinking and Driving Advertising Campaign With a Sample 
Survey and Time Series Intervention Analysis. Journal of the American Statistical Association, 88(421), 50-56.

National Highway Traffic Safety Administration (2007). Evaluation of the national impaired driving high-visibility enforcement campaign: 2003-2005.

Ogazi, C., \& Edison, E. (2012). The drink driving situation in Nigeria. Traffic Injury Prevention, 13(2), 115-119. doi:10.1080/1 5389588.2011.645097

Ogbonne, I. (2019). Cutting the head as cure for headache: Exploring the economic impact of Niger Delta Militancy on host communities. Ianna Journal of Interdisciplinary Studies, 1,1-10

Olijo, I. (2020). Nigerian media and the global competition on aCOVID-19vaccine: Do media reports promote contributions from African countries? Ianna Journal of Interdisciplinary Studies, 2 (1), 1-16.

Ontario Agency for Health Protection and Promotion (2015). Effectiveness of approaches to communicate alcohol-related messages. Retrieved from www.publichealthontario.ca/en/.../ AlcoholRelated Health Messaging 2015

Onyemaechi, N. O. C., \& Ofoma, U. R. (2016). The public health threat of road traffic accidents in Nigeria: A call to action. Annals of Medical and Health Sciences Research, 6(4), 199-204.

Peden, M. (2005). Global collaboration on road traffic injury prevention. International Journal of Injury. Contr. Safety Promotion, 12: 85-91.

safety advertising: The role of the third-person effect, gender, and age. Transportation Research Part F 10, 48-60

Razmara, A., Aghamolaei, T., Madani, A., Hosseini, Z., \& Zare, S. (2018). Prediction of safe driving Behaviours based on health belief model: the case of taxi drivers in Bandar Abbas, Iran. BMC Public Health, 18(1). doi:10.1186/s12889-018-5300-5

Regan, M. A., \& Mitsopoulos, E. (2001). Understanding passenger influences on driver behaviour: Implications for road safety and recommendations for countermeasure development. Retrieved from https://www.monash.edu/_data/assets/ pdf_file/0004/216436/Understanding-passenger-influenceson-driver-behaviour-implications-for-road-safety-andrecommendations-for-countermeasure-development.pdf

Shams, M., Shojaeizadeh, D., Majdzadeh, R., Rashidian, A., \& Montazeri, A. (2011). Taxi drivers' views on risky driving behavior in Tehran: A qualitative study using a social marketing approach. Accident Analysis \& Prevention, 43(3), 646-651. doi:10.1016/j.aap.2010.10.007

Tay, R. (2002). Exploring the Effects of a Road Safety Advertising Campaign on the Perceptions and Intentions of the Target and Nontarget Audiences to Drink and Drive. Traffic Injury Prevention, 3(3), 195-200. doi:10.1080/15389580213651

Tay, R. (2005). The effectiveness of enforcement and publicity campaigns on serious crashes involving young male drivers: Are drink driving and speeding similar? Accident Analysis E Prevention, 37(5), 922-929. doi:10.1016/j.aap.2005.04.010

Wang, S.H., Chen,Y.Y., Huang, J.L., Zhou, Y.Y. and Lu, Y. (2018) Research on the Drunk Driving Traffic Accidents Based on Logistic Regression Model. Open Journal of Applied Sciences, 8, 487-494. https://doi.org/10.4236/ojapps.2018.811039

Welcome, M. O., \&Pereverzev, V. A. (2010). Limit of blood alcohol concentration: A major problem to solve in Nigeria. European Psychiatry, 25(Suppl 1), 544.

Whittam, K. P., Dwyer, W. O., Simpson, P. W., \& Leeming, F. C. (2006). Effectiveness of a Media Campaign to Reduce traffic crashes involving young drivers. Journal of Applied Social Psychology, 36(3), 614-628. doi:10.1111/j.00219029.2006.00021.x

WHO (2009). WHO public hearing on harmful use of substances. Retrieved from www.who.int//substance abuse

WHO. (2004). World Report on Road Traffic Injury Prevention. Geneva: World Health Organization.

Winpenny, E., Patil, S., Elliott, M., Dijk, L. V., Hinrichs, S., Marteau, T., \& Nolte, E. (2012). Assessment of young people's exposure to alcohol marketing in audio-visual and online media. RAND Europe Westbrook Centre Milton Road Cambridge CB4 1YG United Kingdom.

Worden, J. K., Waller, J. A., \& Riley, T. J. (1975). The Vermont public education campaign in alcohol and highway safety: a final review and evaluation (CRASH report I-5). Waterbury: Vermont Department of Mental Health. 